\title{
Olhos de ver, ouvidos de ouvir, mãos de fazer: oficinas de atividades em Terapia 0cupacional como método de coleta de dados
}

Observar, entrevistar, interagir, registrar. Conviver, compartilhar, entender, compreender - e interpretar! Esse é o processo das pesquisas qualitativas, que buscam a singularidade, o próprio e o apropriado pelo sujeito, na medida em que este constrói e é construído pelo contexto em que está inserido.

É preciso olhos de ver mais que de olhar. É preciso ouvidos de ouvir mais que de escutar. É preciso que se disponha o pesquisador a despir-se de si mesmo, quanto possível, para vestir-se da experiência do outro, do olhar do outro, do sentir do outro. Depois, então, vestir-se novamente, mas com as impressões recolhidas da experiência alheia, e construir um discurso sobre tudo isso.

No entanto, se os olhos nem sempre são de ver e os ouvidos nem sempre de ouvir, as mãos... Ah! As mãos são e serão sempre de fazer! Quando as mãos fazem é que nos reconhecemos, nos revelamos, para nós e para os outros. É quando somos mais nós mesmos, pura e simplesmente. Se os olhos enganam, se os ouvidos tapeiam, as mãos nunca mentem.

É através do fazer no mundo que o ser humano constrói a si mesmo. É através do fazer que sentidos se revelam, se tornam fatos (feitos!), visíveis e explicáveis, mesmo que não conscientemente percebidos. No momento da ação, as defesas, as amarras mentais ou comportamentais se afrouxam e o sujeito permite a si mesmo expressar-se.

Em terapia ocupacional, o fazer ocupa lugar central. É o elemento organizador e ordenador de toda prática profissional e, pensamos, pode vir a ocupar também um lugar importante na pesquisa.

Esse processo, se bem conduzido, associado às outras formas de apreensão, permite, ao pesquisador terapeuta ocupacional, fazer uma leitura do universo daquele que faz de uma forma mais ampla, complementando, corroborando ou contradizendo os dados obtidos por meio da observação (participante ou não), da entrevista ou da ação conjunta.

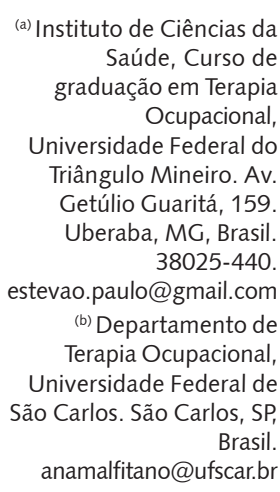


Trabalhamos dessa forma em nossa dissertação de mestrado ${ }^{2}$, junto a jovens moradores da periferia de uma cidade de médio porte do interior paulista, frequentadores de um Centro da Juventude local. Buscamos compreender as formas como esses jovens entendem e explicam, para eles mesmos e para os outros, o fenômeno das drogas em seus cotidianos. A imersão nesse campo de pesquisa se deu por meio de nossa inserção nas ações propostas pelo Projeto METUIA ${ }^{(c)}$, Núcleo UFSCar, junto aos jovens estudados. Os dados foram obtidos por meio de observação participante, entrevistas e oficinas de atividades ${ }^{4}$, nas quais exploramos as mesmas temáticas da entrevista (identidade, cotidiano e drogas), a partir de atividades expressivas como: colagem, poesia coletiva e teatro.

A seguir, reproduzimos o material elaborado por um dos jovens, na oficina de atividades, com a temática "identidade", a primeira que fizemos. Os participantes desta oficina, em número de três, já haviam sido entrevistados e faziam parte das interações participativas que realizávamos no campo. Nesta oficina, como aquecimento, utilizamos um vídeo sobre identidade. Em seguida, discutimos sobre identidade como sendo aquilo que nos define, nos caracteriza, nos identifica. Então lhes apresentamos uma série de imagens com bandeiras de países e de clubes de futebol e sugerimos que eles construíssem, com colagens de recortes de revistas, a bandeira pessoal de cada um, o que os identifica, o que diz "Eu sou" de cada um.

Saulo(d), um jovem de 15 anos, negro, fala contida, corpo franzino, compôs sua “bandeira pessoal" com duas imagens, conforme reproduzido na Figura 1.

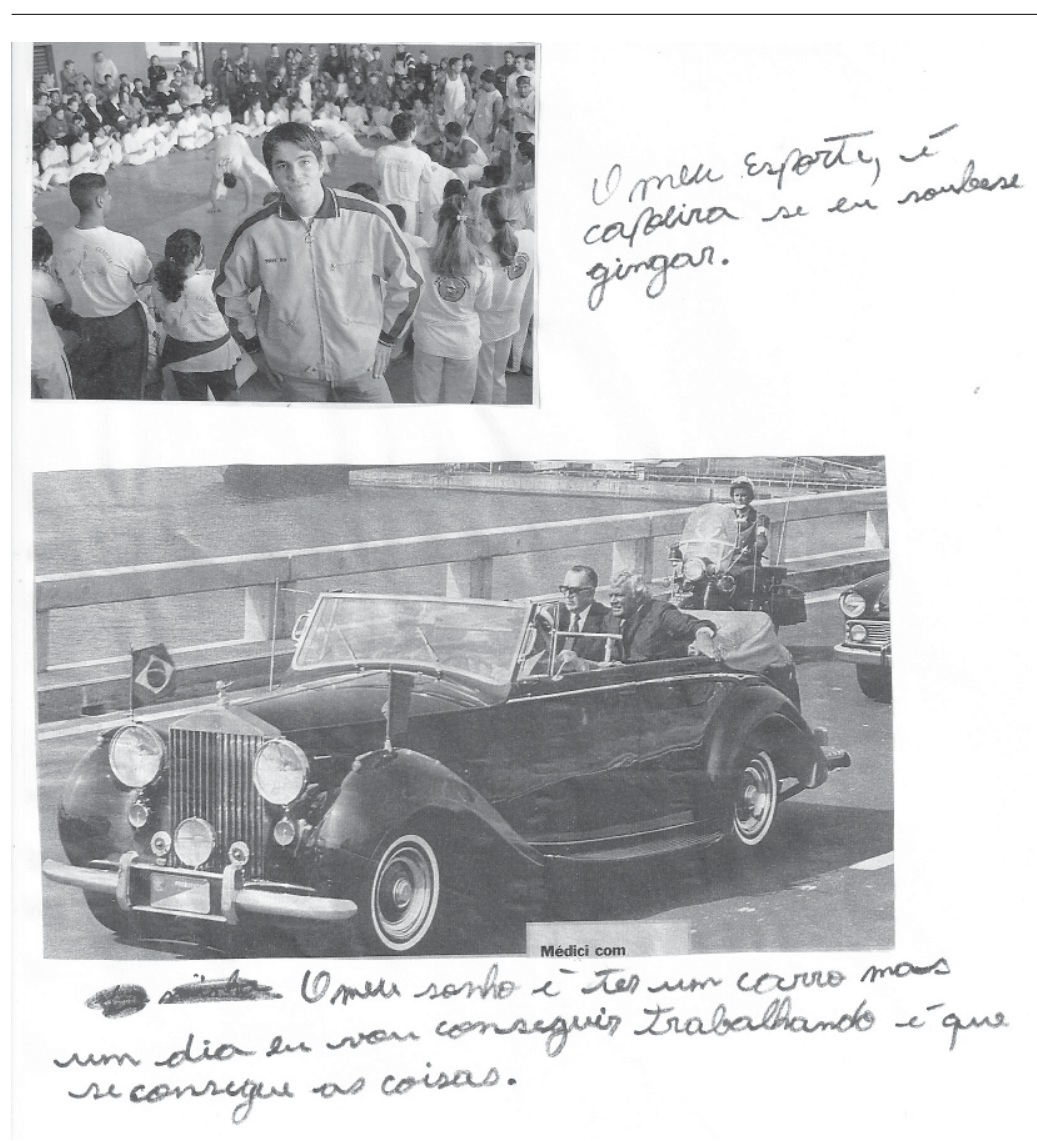

Figura 1. "Bandeira pessoal" de Saulo (c) O Projeto METUIA tem se dedicado à realização de estudos e pesquisas, à formação de estudantes de graduação e pós-graduação e à implementação de intervenções no campo social que busquem a inovação por meio da criação de novas metodologias participativas, assim como da discussão sobre o papel social dos técnicos, em especial do terapeuta ocupacional,

dedicando-se ao enfrentamento das problemáticas contemporâneas da sociedade brasileira. É formado, atualmente, por professores,

estudantes e técnicos da Universidade Federal de São Carlos, da Universidade de São Paulo e da Universidade Federal de São Paulo ${ }^{3}$.

(d) Todos os nomes próprios aqui empregados são fictícios. 


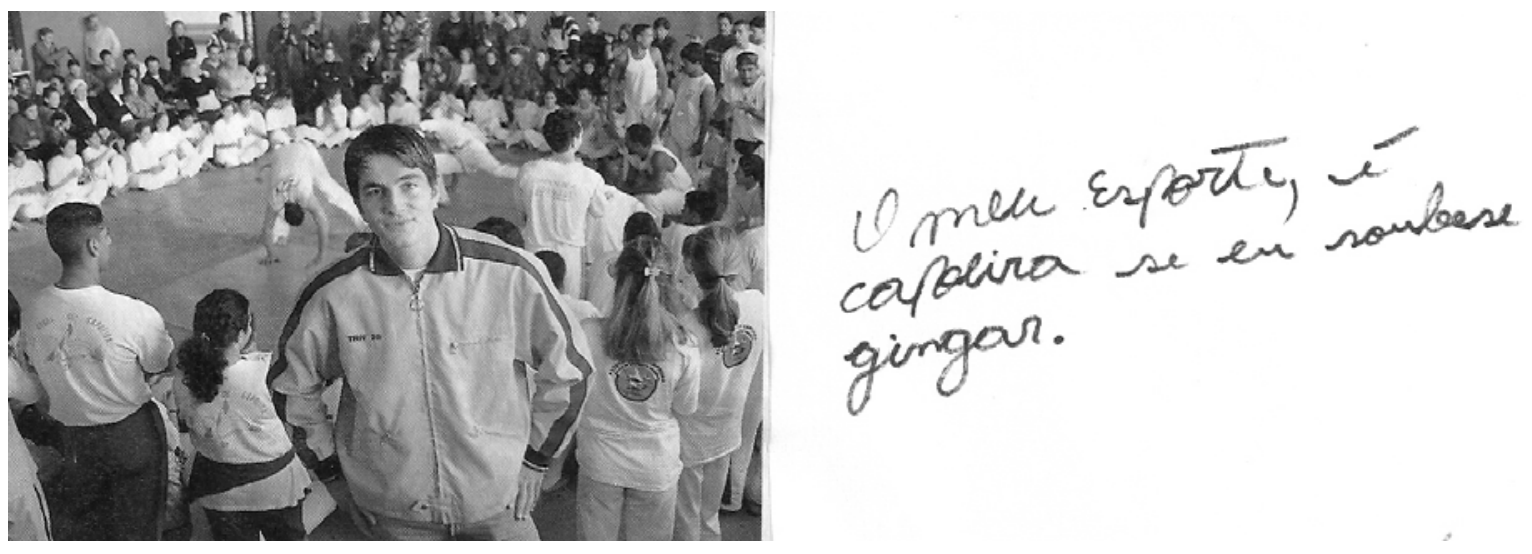

Figura 2. "Bandeira pessoal" de Saulo (detalhe)

Na imagem, um rapaz branco, trajando uma jaqueta esportiva, posa sorridente para a foto. Ao fundo, um grande número de pessoas observa uma roda de capoeira. No lado direito da folha, Saulo escreve: "O meu esporte é capoeira se eu soubese gingar" (mantida aqui sua própria grafia).

Saulo utiliza a imagem de um esporte dinâmico, que requer força, flexibilidade e muita ginga, ou certo "jogo de cintura" para executar de maneira adequada os movimentos. Requer ritmo, percepção do outro, para não ser atingido, e muita criatividade. É assim que ele, na atividade, se identifica. Mas Saulo confessa que não sabe gingar. Ele adota uma imagem para dizer de si, mas que não é para si.

Saulo, à época da pesquisa, cursava o oitavo ano (antiga $7^{\mathrm{a}}$ série) do Ensino Fundamental, tendo repetido um ano. Morava com sua mãe, o irmão e o padrasto. O pai estava preso por tentativa de homicídio. Passava suas tardes no Centro da Juventude no bairro onde mora, jogando futebol, por "não ter nada para fazer". Em conversa sobre seus sonhos, disse: "Não tenho sonho ainda".

A escolha de Saulo pela imagem da roda de capoeira com um jovem em primeiro plano, que se destaca dos demais elementos da cena, somada à frase escrita e ao que ele disse na oficina, nos fornecem uma visão complementar do universo cotidiano desse garoto, mostrando, ou sugerindo, o entendimento de sua condição de jovem pobre, da periferia, de quem os direitos de participação social e de exercício da cidadania são cerceados o tempo todo. Ele "é" o que ele "não pode ser".

Outra imagem escolhida por Saulo reforça a indefinição, a incerteza quanto ao lugar a ser ocupado por ele no futuro. Na foto em preto e branco, aparece um carro conversível luxuoso no qual, além do motorista, estão dois homens de terno e gravata (trata-se do ex-presidente da República Emílio Garrastazu Médici e do ex-ministro Mário Andreazza). No paralama direito dianteiro do veículo, há uma bandeira do Brasil. Ao fundo, vê-se um policial em uma moto, como que a escoltar ou guarnecer o automóvel. Abaixo da foto, Saulo escreveu: "Meu sonho é ter um carro mas um dia eu vou conseguir trabalhando é que se consegue as coisas". O fluxo da frase, sem pontuação, sugere uma dinâmica de pensamentos que vão se sobrepondo, quase que se atropelando, onde sonho, realidade e esperança se misturam. Ao sonho de ter um carro, símbolo de poder e liberdade, sobrevém a realidade, logo em seguida contraposta pela esperança ("mas um dia eu vou conseguir"), condicionada ao código social do trabalho e do esforço pessoal. 


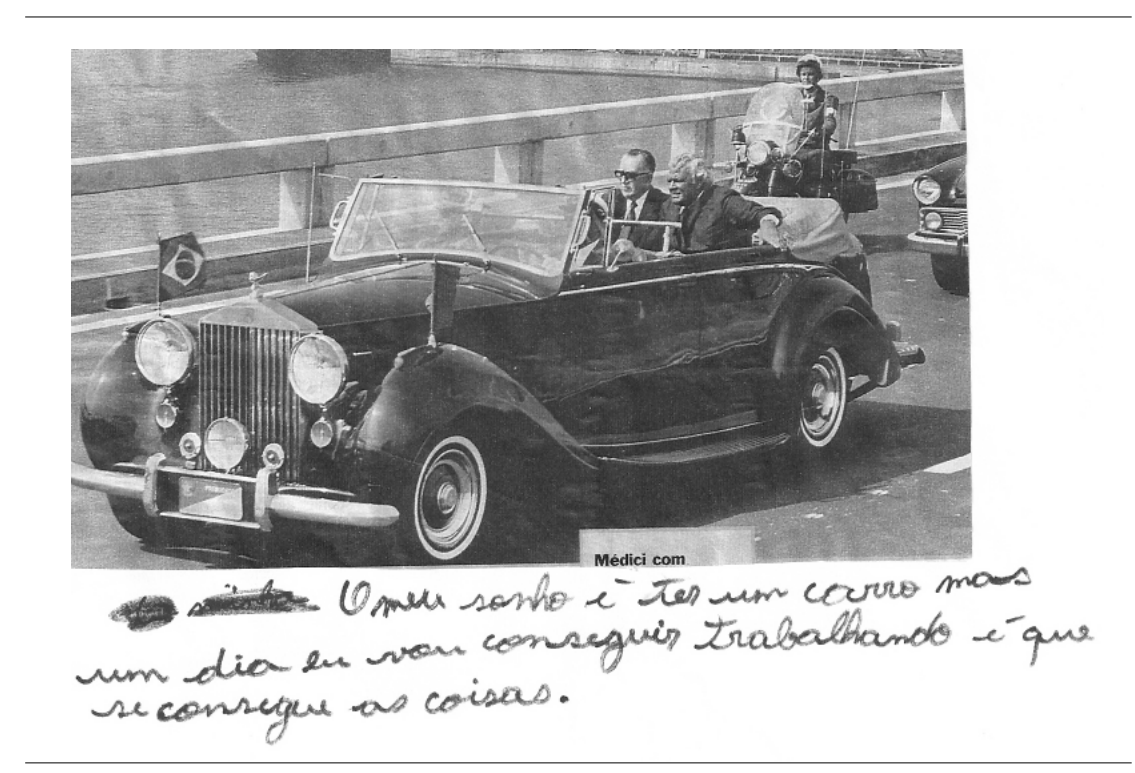

Figura 3. "Bandeira Pessoal" de Saulo (detalhe)

De novo, o que o identifica (ou com o que ele se identifica) são coisas alheias à sua experiência cotidiana. Saulo diz não ter sonhos ainda, mas sua "identidade" é toda feita de "sonhos", no sentido do irreal, do impalpável, do não-existente. Para ele, o que o define é o devir, o vir-a-ser, o vir-a-ter. Seu presente é incerto, instável, inseguro. O dele e de tantos jovens como ele.

Outra atividade que realizamos e que cabe destaque aqui foi a oficina sobre a temática "Cotidiano". Trabalhamos com a técnica de poesia coletiva, na qual, a partir de um tema sugerido pelo grupo, cada um dos participantes, em roda, contribuía com uma palavra ou uma frase sobre o tema. As frases eram anotadas por nós na sequência em que eram ditas. Foram feitas tantas rodadas quantas foram necessárias até que o grupo estivesse satisfeito ou se esgotassem as intervenções. Terminado esse processo, as poesias eram lidas para todos. Foram compostas, no total, nove poesias, das quais destacamos uma. As letras entre parênteses indicam seus autores.

\section{O MEU FUTURO}

Quero o melhor ( $\mathrm{T}$ )

Ser feliz $(H)$

Família (D)

Estar sempre ao lado de quem eu amo (T)

Estudar $(\mathrm{H})$

O futuro... Não sei! (D)

Crescer profissionalmente $(\mathrm{T})$

Ao lado dos meus amigos $(\mathrm{H})$

O que vou falar? (D)

Poder viver $(\mathrm{T})$

Não sei $(H)$

Continuar (D) 
Participaram desta oficina três jovens, sendo duas moças, Taís e Helena, e um rapaz, Daniel. A poesia revela perspectivas e expectativas diferentes em relação ao futuro de cada um.

Taís tem 15 anos, estuda num colégio particular no centro da cidade, e sonha em seguir a carreira militar na Marinha ou na Aeronáutica. Embora resida na mesma região que os demais participantes da pesquisa, constrói sua rede de relações apenas com os colegas de escola, chegando a ser hostilizada por algumas garotas do bairro durante as atividades de que participa no Centro da Juventude.

Helena tem 17 anos, trabalha e estuda, cursando o terceiro ano do Ensino Médio. Planeja continuar seus estudos, ingressando numa faculdade. Ainda não decidiu qual carreira quer seguir, mas planeja seu futuro com essa perspectiva.

Já Daniel tem 23 anos, cursou até a $6^{\mathrm{a}}$ série (atual $7^{\circ}$ ano) do Ensino Fundamental. Não trabalha, mora com a mãe e o irmão. Às vezes, consegue alguns "bicos" em trabalhos que exigem pouca qualificação, porém nada fixo. É um jovem bastante perspicaz e inteligente e faz uma leitura bastante apurada de sua realidade cotidiana. Conhece a todos no bairro onde mora, bem como as relações estabelecidas entre os moradores daquela comunidade. Passa os dias no Centro da Juventude jogando bola e participando das atividades do Projeto METUIA. Seu planejamento futuro se resume a um aparentemente eterno "entregar currículo".

Os versos da poesia trazem o contraponto estabelecido pelas perspectivas de Daniel, de um lado, e de Taís e Helena, de outro. Enquanto as garotas, cada uma à sua maneira, expressam uma visão de futuro cheia de planos ("Quero o melhor", "Ser feliz", "Estar sempre ao lado de quem ama", "Estudar"), Daniel traz um futuro incerto pontuado por um presente marcado por limitações e precariedades. Espera para o futuro o mesmo que para o presente: "Continuar!" Seguir seu caminho, passo após passo, sem saber ao certo onde irá chegar. A única certeza, o único ponto de apoio que Daniel parece enxergar nesse mar de dúvidas é a família, sua primeira contribuição para a poesia. É nas relações próximas e solidárias ${ }^{5}$ que ele encontra algum sentido e, talvez, forças para continuar.

As duas atividades que apresentamos aqui demonstram, de maneira complementar aos dados obtidos pelas outras metodologias que utilizamos, a condição social daqueles jovens como moradores das periferias brasileiras. Convivem, na mesma realidade cotidiana, jovens restritos no exercício de sua cidadania e de seus direitos fundamentais, sujeitados a um presente marcado por incertezas, e cujos projetos de futuro, quando não inexistentes, são dominados por perspectivas frouxas. Jovens que, embora também possam sofrer restrições em seus direitos devido à sua classe social, vislumbram horizontes um pouco mais definidos. Se todo amanhã é incerto, para alguns ele é mais incerto que para outros.

Destaca-se que a experiência de realização de oficina de atividades, a partir da terapia ocupacional social ${ }^{6}$, possibilitou não "apenas" a produção de ações com jovens pobres residentes nas periferias urbanas, mas, também, apresentou-se como um importante e potente recurso para a apreensão de suas realidades no âmbito da pesquisa.

Considera-se fundamental, para o campo da pesquisa social em geral, e para a pesquisa em terapia ocupacional em particular, a compreensão de que o que é experimentado, produzido e agenciado na prática terapêutico-ocupacional pode ofertar "materiais", "dados", "realidades", "subjetividades" e "objetividades" que contribuam, a partir do fazer, com diferentes maneiras de olhar e ouvir. Tais "dados" podem ser analisados, no âmbito da pesquisa, sob a perspectiva dinâmica da construção do conhecimento.

\section{Colaboradores}

Os autores participaram, igualmente, de todas as etapas de elaboração do artigo. 
OLHOS DE VER, OUVIDOS DE OUVIR, MÃOS DE FAZER: ...

\section{Referências}

1. Castro ED, Lima EMFA, Brunello MIB. Atividades humanas e terapia ocupacional. In: De Carlo MMRP, Bartalotti CC. Terapia ocupacional no Brasil: fundamentos e perspectivas. São Paulo: Plexus; 2001. p. 41-59.

2. Pereira PE. "Aí!? Tá me tirando?" - o que dizem jovens pobres de São Carlos sobre si mesmos e a temática das drogas [dissertação]. São Carlos (SP): Universidade Federal de São Carlos; 2012.

3. Silva CR. Políticas públicas, educação, juventude e violência na escola: quais as dinâmicas entre os atores envolvidos? [dissertação]. São Carlos (SP): Universidade Federal de São Carlos; 2007.

4. Lopes RE, Borba PLO, Silva CR, Malfitano APS. Terapia ocupacional no campo social no Brasil e na América Latina: panorama, tensões e reflexões a partir de práticas profissionais. Cad Terap Ocup UFSCar. 2012; 20(1):21-32.

5. Castel R. As metamorfoses da questão social. 8a ed. São Paulo: Vozes; 2009.

6. Barros DD, Ghirardi MIG, Lopes RE. Terapia Ocupacional Social. Rev Ter Ocup Univ São Paulo. 2002; 13(3):96-103. 
Os métodos de coleta de dados em pesquisa podem ser múltiplos e envolvem diferentes técnicas e abordagens. Partindo da perspectiva teórico-metodológica da Terapia Ocupacional Social, apresenta-se o relato de fragmentos de oficinas de atividades utilizadas como recurso para apreensão da realidade de jovens pobres residentes em periferias urbanas, no desenvolvimento de uma determinada pesquisa. A partir de imagens e poesias produzidas pelos jovens colaboradores, em atividades realizadas em um centro de juventude, conclui-se que as oficinas terapêuticoocupacionais possibilitaram não "apenas" a produção de ações com aqueles jovens, mas também apresentaram-se como um importante e potente recurso para a apreensão de suas realidades no âmbito da pesquisa.

Palavras-chave: Terapia Ocupacional. Oficina de atividades. Pesquisa. Juventude pobre.

Eyes to see, ears to hear, hands to do: activity workshops on Therapy Occupacional as a data-gathering method

Data-gathering methods in research may be multiple and involve many techniques and approaches. Starting from the theoretical and methodological perspective of social occupational therapy, a report on fragments of activity workshops that were used as a resource for understanding the realities of adolescents living in peripheral urban areas, in developing a particular research project is presented. Through images and poetry produced by adolescents participating in activities at a youth center, it is concluded that occupational therapeutic workshops not only enable production of actions among these adolescents, but also are an important and potent resource for comprehending their realities within the scope of research.

Keywords: Occupational therapy. Activity workshop. Research. Poor adolescents.

Ojos de ver, oídos de oír, manos de hacer: talleres de actividades en Terapia Ocupacional como método de colecta de datos

Los métodos de colecta de datos en las investigaciones pueden ser múltiplos y envuelven diferentes técnicas y abordajes. Partiendo de la perspectiva teóricometodológica de la Terapia Ocupacional Social se presenta el relato de fragmentos de talleres de actividades utilizados como recurso para la percepción de la realidad de jóvenes pobres residentes en periferias urbanas, en el desarrollo de un estudio determinado. A partir de imágenes y poesías producidas por los jóvenes colaboradores, en actividades realizadas en un centro para la juventud, se concluye que los talleres terapéutico-ocupacionales posibilitaron no "solo" la producción de acciones con esos jóvenes, sino que también se presentaron como un importante y potente recurso para la percepción de sus realidades en el ámbito de la investigación.

Palabras clave: Terapia ocupacional. Taller de actividades. Pesquisa. Juventud pobre.

Recebido em 23/09/13. Aprovado em 25/01/14

(2) Interface comunicaçōo saúde educas̆ăo 
